\title{
EFEITO DO DÉFICIT HÍDRICO NA TRANSPIRAÇÃO E RESISTÊNCIA ESTOMÁTICA DA MANGUEIRA ${ }^{1}$
}

\author{
MANOEL TEIXEIRA DE CASTRO NETO ${ }^{2}$
}

RESUMO - O processo de indução floral da mangueira no Nordeste brasileiro, mediante o uso do déficit hídrico, não tem dado resultado satisfatório, principalmente pelo manejo inadequado da irrigação. O processo transpiratório e a resistência estomática da mangueira refletem a condição hídrica da planta. O monitoramento destes parâmetros fisiológicos na mangueira, durante o período de repouso fisiológico e irrigado, sugere que a indução floral por déficit hídrico não é eficiente devido ao manejo incorreto da irrigação.

Termos para indexação: manga, déficit hídrico, transpiração, resistência estomática, indução floral.

\section{EFFECT OF WATER DEFICIT ON THE TRANSPIRATION AND STOMATAL RESISTANCE OF MANGO TREE}

ABSTRACT - Flowering induction of mango growth at the Northeast Brazil has not given satisfactory results mainly due to inadequate irrigation management. Transpiration and stomatal resistance of mango trees can reflect the water status of the plant. Monitoring the transpiration and stomatal resistance of mango trees during water deficit and irrigation period suggests that the flower induction by water deficit is not efficient due to incorrect irrigation management.

Index terms: Mango, water deficit, transpiration, stomatal resistance, flower induction

\section{INTRODUÇÃO}

A cultura da manga (Mangifera indica L.) tem-se destacado na fruticultura da região do Submédio São Francisco, onde, apesar de ser cultivada sob diferentes sistemas de irrigação, ainda enfrenta déficit hídrico, o qual afeta seu crescimento, desenvolvimento e produção. Nessa região, as condições edafoclimáticas são muito favoráveis à exploração da cultura. A alta disponibilidade de energia solar, água para a irrigação, temperaturas adequadas ao crescimento dos frutos e baixa umidade relativa do ar são alguns dos fatores que contribuem para o sucesso da cultura na região. Sob clima tropical, o processo de indução floral depende da ativação de fatores fisiológicos que reforçam o estímulo floral da mangueira. A indução floral da mangueira mediante a utilização do déficit hídrico tem sido sugerida por alguns autores (Chacko, 1986; Schaffer et al., 1994; Bally et al., 2000). Entretanto, este método apresenta muita controvérsia e é questionada por pesquisadores, como: Davenport (1993), Núñez_Elisea and Davenport (1994). Em relação ao efeito do déficit hídrico como promotor da indução floral, Castro Neto (1995) tem discutido que o principal problema é que a aplicação do déficit hídrico não tem sido realizada de maneira correta, ficando a planta com bastante água ainda disponível para o crescimento vegetativo. $\mathrm{O}$ autor fundamenta sua sugestão no fato de que os pomares situados sob as mesmas condições, mas tratados com déficit hídrico por excesso de água, apresentam uma floração satisfatória. Recentemente, Pongsomboon et al. (1997) demonstraram que a floração foi correlacionada com o baixo potencial hídrico da folha da mangueira durante o período de repouso fisiológico.

Outro ponto de discussão na literatura é a aplicação de nitrato de potássio para a indução floral. Aplicações de nitrato de potássio na concentração de 3 a 6 \% têm sido usadas para antecipar a floração. O nitrato não é um indutor floral, mas age como um catalisador, antecipando a floração da mangueira (Castro Neto, 1995).

O comportamento da mangueira sob condições subtropicais é relativamente bem entendido (Chacko, 1986); entretanto, pouco se conhece como a mangueira se comporta em climas tropicais. Sob altas temperaturas e disponibilidade de água no solo, a mangueira tende a vegetar.

Schaffer et al. (1994) sugerem que a transpiração e a assimilação líquida de $\mathrm{CO}_{2}$ podem ser usadas como parâmetros para o estudo das relações hídricas da mangueira, haja vista que a transpiração é um bom indicador da disponibilidade de água na planta. Em uma situação de boa disponibilidade de água, as plantas cultivadas geralmente apresentam altas taxas de transpiração (Salisbury \& Ross, 1992). À medida que a água do solo se torna escassa, a planta começa a reduzir sua taxa transpiratória para a dimi- nuição da perda de água e economia da água disponível no solo. A transpiração da mangueira tem sido correlacionada à umidade relativa e à pressão de déficit de vapor (Schaffer et al., 1994).

Para entender-se melhor como a mangueira se comporta nas condições climáticas do Submédio São Francisco, alguns parâmetros fisiológi$\cos$, como transpiração e resistência estomática, foram medidos ao longo do ano, durante períodos distintos do ciclo da planta.

\section{MATERIAL E MÉTODOS}

O trabalho foi realizado na região do Submédio São Francisco, em um pomar de 23 ha de manga da variedade Tommy Atkins, com 8 anos de idade, plantada no espaçamento convencional de 10x10 m e irrigada por aspersão. A região do Submédio São Francisco possui uma precipitação média anual de $350 \mathrm{~mm}$ concentrada nos meses de janeiro a abril, temperatura variando de $12 \mathrm{a} 38^{\circ} \mathrm{C}$, com média anual de $26^{\circ} \mathrm{C}$, insolação média anual de 7,3 h/dia, com valor mínimo de 5,9 h/dia, nos meses de maio a junho, e valor máximo de $9 \mathrm{~h} /$ dia no mês de outubro. A evaporação potencial oscila entre 1800 e $2000 \mathrm{~mm} /$ ano, enquanto a média anual de umidade relativa é de $60 \%$, sendo o valor mínimo de $40 \%$ alcançado no mês de outubro e valor máximo de $76 \%$ alcançado no mês de abril.

$\mathrm{O}$ monitoramento correspondeu à medição de alguns parâmetros fisiológicos, como a transpiração, resistência estomática e potencial hídrico. As medições foram realizadas semanalmente ou com intervalos de 15 dias, durante o período de déficit hídrico (abril a maio) e durante o período de irrigação, onde as observações foram feitas antes e 24 horas após cada irrigação. As medições de transpiração e resistência estomática, bem como temperatura da folha, foram feitas com um porômetro portátil(LI-1600, LICor Nebraska, USA).

As medições foram realizadas para folhas expostas diretamente ao sol e para folhas do lado que se encontravam à sombra. A folha amostrada foi a primeira folha madura a partir do ápice do ramo.

\section{RESULTADOS E DISCUSSÃO}

Os resultados obtidos para o comportamento da resistência estomática apresentado na Figura 1 mostram uma grande flutuação nas medições feitas à sombra, independentemente do período amostrado. Esta variação nas medições foi maior para as folhas situadas à sombra durante a realização das medições. Este comportamento para a resistência estomática pode ser explicado devido à resposta dos estomatos à variação da condição

\footnotetext{
${ }^{1}$ (Trabalho 024/2002). Recebido: 07/03/2002; Aceito para publicação: 07/03/2003.

Eng $^{\circ}$ Agr $^{\circ}$, Ph.D., Pesquisador da EMBRAPA Mandioca e Fruticultura, Caixa postal 007, Cruz das Almas-BA 44380-000, Fone: (075) 621-2120, castro@cnpmf.embrapa.br.
} 
luminosa que, certamente, não se apresenta homogênea para todas as folhas apesar do empenho em manter as mesmas condições para as amostragens realizadas. Para as amostragens sob pleno sol, houve menor variação.

A resistência estomática das folhas sob sombreamento e expostas ao sol é diferente, sugerindo que, para plantas de porte alto, como é o caso da mangueira, deve-se considerar o que está ocorrendo em ambos os lados da copa da planta. Considerando o comportamento da resistência estomática durante o período de déficit hídrico, ou repouso fisiológico (abril a final de maio, Fig 1), e o período de irrigação (final de maio a final de agosto, Fig. 1), nota-se que a resistência das folhas expostas ao sol foi maior para o período de irrigação. Inicialmente, a resistência foi maior para o período de irrigação, sugerindo que, ao sair do déficit hídrico, a planta começa com uma economia de água. Com a continuação da irrigação, a resistência decresce, embora permaneça superior ao período anterior (Figura 1).

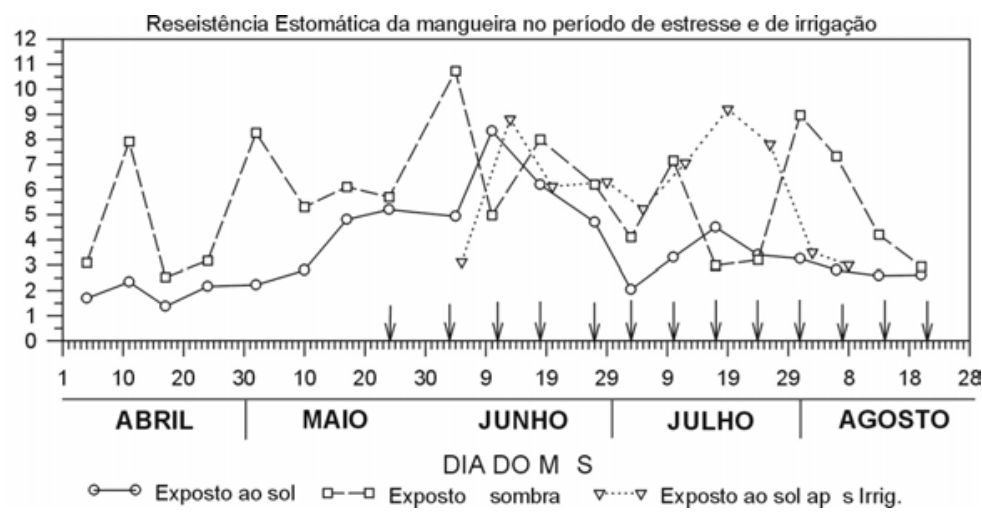

FIGURA 1 - Comportamento da resistência estomática da mangueira para o período de déficit hídrico, ou repouso fisiológico, e para a época irrigada. (Setas indicam as datas das irrigações).

As observações da resistência estomática após as irrigações mostram que estas não foram reduzidas com o irrigação. Estes dados sugerem ineficiência da irrigação em promover diminuição da resistência estomática da mangueira.

Análise dos dados de transpiração (Figura 2) confirmam os resultados obtidos para a resistência estomática. A transpiração foi menor para o período de irrigação (final de maio a agosto) que para o período de déficit hídrico (abril a final de maio). Como a transpiração em ambos lados da copa, tanto exposta ao sol como exposta à sombra, apresentara a mesma tendência (Figura 2), o efeito causando redução na transpiração independe das condições de luminosidade em ambos os lados da copa da planta. Com relação a esse fato, a redução da transpiração pode estar sendo provocada por um fator afetando a disponibilidade de água para a planta. Neste sentido, sugere-se que as irrigações, causando uma injúria para a mangueira por excesso de água, promovem a redução do oxigênio do solo utilizado na respiração radicular.

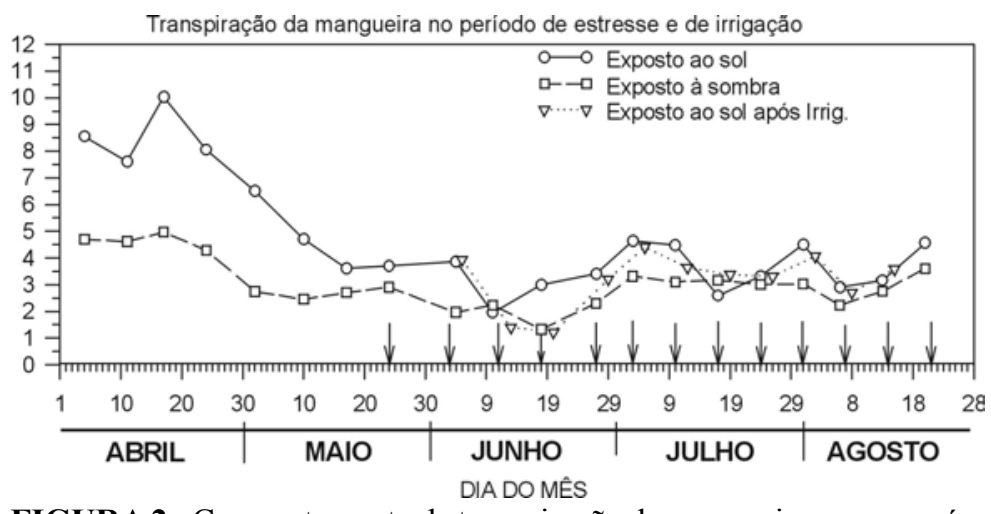

FIGURA 2 - Comportamento da transpiração da mangueira para o período de déficit hídrico, ou repouso fisiológico, e para a época irrigada. (Setas indicam as datas das irrigações).

Adicionalmente, os dados na Figura 2 indicam altas taxas transpiratórias, sugerindo que a mangueira se encontrava em condição de déficit hídrico com a suspensão da irrigação durante aquele período. Isto sugere que a prática do uso do déficit hídrico como indutor floral está sendo mal utilizada.

A suposição de que as baixas temperaturas que geralmente ocorrem durante o período de junho a agosto, poderiam estar causando a diminuição da transpiração, é descartada, uma vez que a temperatura da folha para ambos os períodos permaneceram aproximadamente iguais (Figura 3).

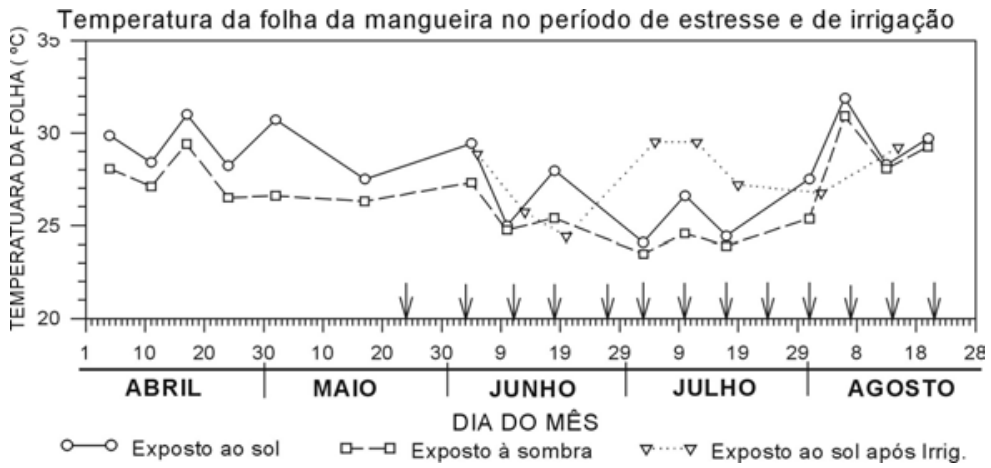

FIGURA 3 - Comportamento da temperatura da folha da mangueira para o período de déficit hídrico, ou repouso fisiológico, e para a época irrigada. (Setas indicam as datas das irrigações).

Observação da resistência estomática e da transpiração ao longo do dia, para dois dias característicos da época de déficit hídrico e da época irrigada (Figura 4), demonstra muito pouca diferença entre as variáveis para os dois períodos estudados. Mais uma vez, os dados sugerem que as irrigações aplicadas para disponibilizar água para a planta não têm sido eficientes.
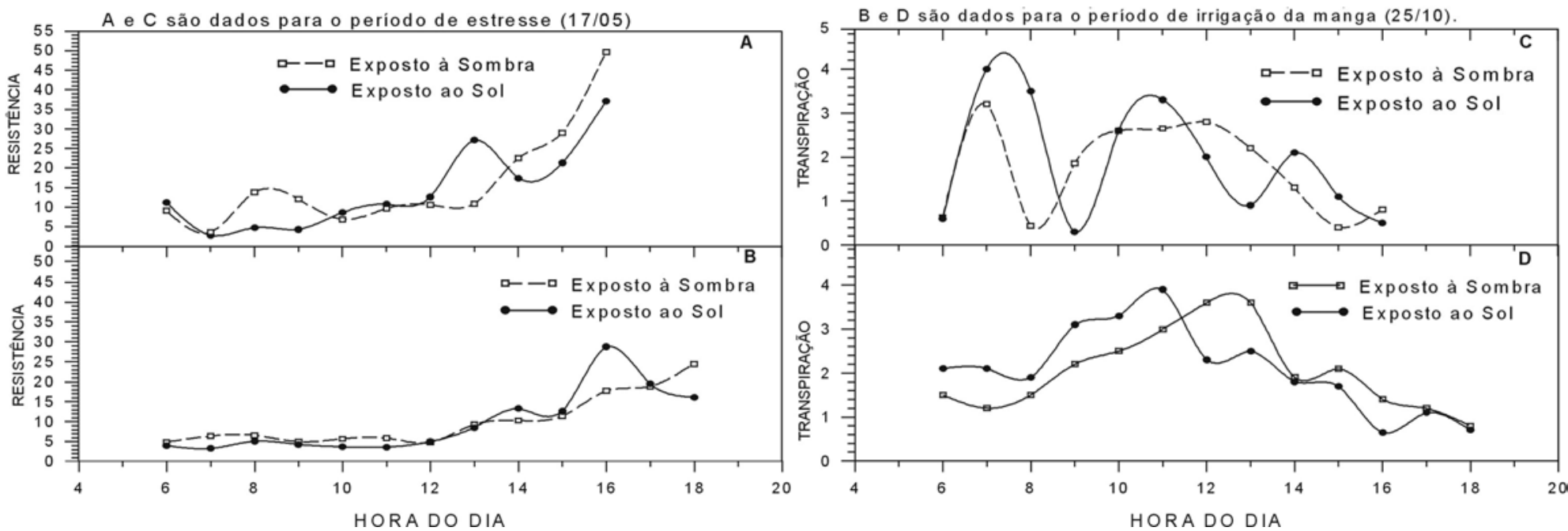

FIGURA 4 - Comportamento da resistência estomática e da transpiração da mangueira, ao longo do dia, para dois dias característicos do período de déficit hídrico, ou repouso fisiológico, e do período irrigado. (A e C são dados do período de déficit hídrico. B e D são dados do período de irrigação). 


\section{CONCLUSÕES}

O processo transpiratório claramente reflete a disponibilidade de água para a planta. Sendo assim, os resultados apresentados neste trabalho demonstram que o déficit hídrico usado para a indução floral da mangueira é feito de maneira incorreta. O presente trabalho sugere que o estresse por suspensão da irrigação seja aplicado da maneira mais rápida possível. Para isto, o solo deve apresentar boa drenagem ou um dreno-trincheira eficiente para a remoção da água de irrigação da área radicular da mangueira. Deve-se evitar o excesso de água na irrigação para não provocar um efeito contrário para a mangueira.

\section{REFERÊNCIAS BIBLIOGRÁFICAS}

BALLY, I.S.E.; HARRIS, M.; WHILEY, A. W. Effect of water stress on flowering and yield of 'Kensington Pride' mango. Acta Horticulturae, Wageninger, v. 1, n. 509, p. 277-281, 2000.

CASTRO NETO, M. T., Aspectos fisiológicos da mangueira sob condições irrigadas. In: EMBRAPA-CPATSA, Informações Técnicas Sobre a Cultura da Manga no Semi-Árido Brasileiro. Petrolina, 1995. p. 83-99.
CHACKO, E. K. Physiology of vegetative and reproductive growth in mango (Mangifera indica L.) trees. Proceedings of the First Australian Mango Research Workshop, 1., Melbourne. 1986, Proceedings...p 54-70.

DAVENPORT, T. Floral manipulation in mangos, In: CONFERENCE ON MANGO IN HAWAII, 1993, Proceedings... p. 54-59.

NÚÑEZ-ELISEA, R.; DAVEMPORT, T.L. Flowering of mango trees in containers as influenced by seasonal temperature and water stress. Scientia Horticulturae, Amsterdam, v. 58, p. 57-66, 1994.

PONGSOMBOON, W.; SUBHADRABANDHU, S.; STEPHENSON, R. A. Some aspects of the ecophysiology of flowering intensity of mango (Mangifera indica L.) cv. Nam Dok Mai in a semi-tropical monsoon Asian climate. Scientia Horticulture, Amsterdam, v. 70, p. 45-56, 1997.

SALISBURY, F. B.; ROSS, C. W. The photosynthesis-transpiration compromise. In: SALISBURY, F. B. ; ROSS, C. W. Plant physiology. 4 nd. California: Wadsworth, 1992. p.66-92.

SCHAFFER, B.; WHILEY, A. W.; CRANE, J.H. Mango. In: SCHAFFER, B.; ANDERSEN, P. C. (Ed.) Handbook of environmental physiology of fruit crops. Florida: CRC Press, 1994. cap. 8, p. 165-197. 